\title{
The Effects of Positive Affirmation and Constructive Criticism on Student Writing and Success
}

\author{
Hayley E.D. Lunseth ${ }^{1}$ \\ Writing across the University of Alberta, $2021^{2}$ \\ Volume 2, pp. 13-16 \\ Published December 2021 \\ Keywords: writing studies education, teacher feedback, constructive feedback, positive affirmation
}

Is it more helpful for an individual such as a teacher to provide a student with constructive criticism or positive affirmations in relation to their writing? Which method is helpful in pushing the student to prosper and which can be detrimental when utilized inappropriately and ineffectively? Do positive affirmations provide students with a false sense of confidence with little knowledge of what they can improve upon, or does constructive criticism dismantle the faith an individual has in their writing capabilities causing them to produce work that is not of their best quality? This paper explores both forms of feedback often employed by educators through the utilization of various research papers and sources to determine which method of response or assessment is most useful in order for a student to reach their full writing potential.

"As teachers, we want above all else for our students to learn and succeed" (Barr \& Tagg, 1995, p. 14 ). A student's success is directly determined by their teacher and the methods they utilize. Two approaches often used when reviewing a student's written work are validation, in the form of positive affirmation, and constructive criticism. It often becomes problematic for a teacher as they decide upon which role to assume in the classroom; whether they be a "friendly supporter", or a "critic" (Edington, 2016, p. 69). Both processes, when expressed towards an individual's writing, evoke a sense of self reflection and allow the individual to develop the motivation to advance themselves as a writer. 
While some individuals believe that the preferable approach is to use positive affirmation, thus providing an individual with a sense of validation and appreciation, others view constructive criticism and the act of critiquing another's work to be the most superior way to motivate others to improve their work (Hattie \& Timperley, 2007, p. 83). Is one approach more effective than another, and what are the effects that result from utilizing either method? More specifically, how is a student's writing affected when their work is critiqued or praised by a superior figure, such as a teacher? Along with the findings from several researchers such as Brown, Payne, Lankewich, \& Cornell (1970), Hattie \& Timperley (2007), William (1998), and my own experiences, both methods are explored thoroughly in order to determine the beneficial results and consequences for each. This allows me to argue that positive affirmation is more beneficial when applied in a situation where an individual is to give feedback regarding a student's piece of writing than its counterpart, constructive criticism, which ultimately causes the student to develop emotions of self-consciousness and defeat. Both methods should be applied towards student writing, but positive affirmation should have a more prominent role in the classroom in order to be most effective.

\section{Positive Affirmation Is Key to Motivating a Student}

Providing a student with verbal acknowledgement for an exceptional piece of work is necessary for the student to gain confidence and to encourage maximum effort. As quoted by Brown, Payne, Lankewich, \& Cornell, "Verbal reinforces that connoted praise or correctness increased the amount of time spent attending to the assigned task" (1970, p. 373). When a student is placed in an environment that they view to be "emotionally safe" and free from harsh criticism, they are able to produce optimal work and reach their full potential (Williams, 1998, p. 15). When an individual is immersed in a setting where they are not concerned about being ridiculed for their efforts towards a task, they develop a sense of confidence and are able to "think outside the box" without worrying about making an error (Williams, 1998, p. 15).

\section{My Experience with Verbal Affirmation}

My experience with the influential force of validation came early in my writing career. I was in tenth grade when I entered the English class of a teacher who was passionate about writing and his students' success. It was after I handed in my first essay on the play Romeo and Juliet by William Shakespeare, that I received the validation that was necessary to gain the confidence to prosper. Mr. Raible confessed that he believed I was one of the few individuals capable of scoring one hundred percent on my grade twelve English diploma. Because I was provided with the incentive I needed to prosper, I was motivated to expand my 
vocabulary, learn how to implement a stronger voice into my writing, and better develop my style. If it were not for this affirmation and positive reinforcement, I would not have been able to win the top academic awards for all three years of high school English, as well as score the exceptional mark that I achieved on my diploma.

\section{Constructive Criticism and Improvement}

It is argued that constructive criticism given by a superior figure motivates a student to gain the knowledge necessary to improve their writing. As demonstrated by Sherman Alexie's previous experiences, by growing up alongside various negative forces that continually criticized him as an individual and his work, Alexie was spurred into greatness and became a well-accomplished writer (2014, p. 28). Similar to receiving validation, criticism can also challenge an individual to accomplish greatness. Research evidence conducted by John Hattie and Helen Timperley at the University of Auckland (2007) has proven that when a student is praised for their performance on a task, nothing is learned; therefore, this method becomes ineffective (p. 85). It is when the student is "receiving information feedback about a task and how to do it more effectively" that change is able to occur (Hattie \& Timperley, 2007, p. 83).

\section{My Experience with Criticism}

My personal experience with effective criticism stems from my grade eleven English class. Unlike the tenth grade, my grade eleven teacher felt indifferent towards my style of writing and often provided me with ways in which I could improve. Although I felt frustrated and confused, I eventually came to the realization that there were new methods available and ways in which I could vary my sentences, unlike I had before.

\section{The Superior Method}

Not all criticism is beneficial. Research done by Baron in 1988 has proven that criticism causes detrimental effects on an individual, as it results in the individual becoming less motivated and developing feelings of "anger and tension" (p. 238). This is why professor Charles Madsen, of Florida State University, campaigns for a "four to one compliment-criticism ratio," as he believes it is the most effective way to motivate students to improve upon themselves, without dismantling their efforts altogether (Brown et al., 1970, p. 373). Since verbal affirmation has proven to be more beneficial when influencing an individual's work, the use of four compliments for every critique given is needed in order to reduce the consequences of too many destructive comments. With this in mind, when an educator is faced with the dilemma of deciding how to respond to a student's paper (Edington, 2016, p.70), they should follow in pursuit of this "rule," as it allows the student to acquire the information necessary to understand their errors and how to further improve, 
but also allows them to develop a sense of self-assurance and validation, thus permitting them to remain motivated.

\section{Conclusion}

Although constructive criticism is necessary in order for a student to improve in areas such as writing, the emotional and academic effects on a student can be devastating. While both methods should be utilized, it is vital that an educator places more importance on positive feedback rather than criticism in order to prevent the student from experiencing frustration and despair. I have found both methods have their place and were advantageous for me in becoming a more effective and confident writer, but my grade ten teacher's words of motivation are what ultimately allowed me to advance my writing. I plan to utilize this research in the future when I, myself, become a high school English teacher.

\section{References}

Alexie, S. (2014). The joys of reading and writing: Superman and me. In E. Wardle and D. Downs (Eds.) Writing about writing: A college reader (2nd ed.) (pp. 128-132). MacMillan.

Baron, R. (1990). Countering the effects of destructive criticism: The relative efficacy of four interventions. Journal of Applied Psychology, 75(3), 234-245. https://doi.org/10.1037/0021-9010.75.3.235

Barr, R., \& Tagg, J. (1995). From teaching to learning. A New Paradigm for Undergraduate Education, 27(6), 12-25. https://doi.org/10.1080/00091383.1995.10544672

Brown, W., Payne, T., Lankewich, C., \& Cornell, L. (1970). Praise, criticism, and race. The Elementary School Journal, 49(1), 373-377.https://doi.org/10.1086/460595

Edington, A. (2016). Split personalities: Understanding the responder identity in college composition. Journal of Response to Writing, 2(1), 75-91. https://scholarsarchive.byu.edu/journalrw/vol2/iss $1 / 5$

Hattie, J., \& Timperley, H. (2007). The power of feedback. Review of Educational Research, 77(1), 81-112. https://doi.org/10.3102/003465430298487

Williams, K., \& Williams, C. (2011). Five key ingredients for improving motivation. Research in Higher Education Journal, 11. http://aabri.com/manuscripts/11834.pdf

(c) $\$($ This work is licensed under CC BY-NC-ND 4.o. To view a copy of this license, visit https://creativecommons.org/licenses/by-nc-nd/4. 